\title{
Kronologis Kejadian Pre Eklampsia Yang Dikaitkan Dengan Penyebab Tidak Langsung Di Karawang
}

\author{
Miftahul Jannah,Fitria Sari, Endang Siti Mawarni \\ Universitas Respati Indonesia, Jl. Bambu Apus I no 3, Cipayung - 13890 \\ Email : miftah@urindo.ac.id
}

\begin{abstract}
Abstrak
Preeklampsia serta eklampsia merupakan salah satu penyakit yang menjadi perhatian khusus pada kasus maternal dan neonatal, karena penyakit preeklampsia dan eklampsia ini adalah salah satu penyebab kematian ibu hamil dan perinatal yang tinggi terutama di negara berkembang. Sampai saat ini penyakit preeklampsia dan eklampsia merupakan "the disease of theories", karena jumlah angka penderita preeklampsia dan eklampsia tetap tinggi dan mengakibatkan angka kesakitan dan kematian maternal yang tinggi. Jumlah data yang ditemukan oleh peneliti kasus ibu yang bersalin dan menderita preeklampsia pada saat persalinannya di Puskesmas Pedes pada tahun 2014 berjumlah 103 kasus (7,1\%), pada tahun 2015 mengalami penurunan sebanyak 3\% menjadi 98 kasus (6,8\%), dan pada tahun 2016 terdapat preeklampsia mencapai 134 kasus $(12,4 \%)$. Adapun tujuan dari penelitian ini adalah untuk mengetahui faktor penyebab dari kejadian pre eklampsia yang banyak terjadi kasus nya saat ini khusus nya dari faktor penyebab tidak langsung seperti : riwayat penyakit ibu, riwayat penyakit keluarga, sosial ekonomi dan keteraturan ANC. Metode yang dipakai dalam penelitian ini adalah dengan pendekatan kuantitatif dengan rancangan Kohort Prospektif, sedangkan Populasi pada penelitian ini adalah ibu hamil trimester 3 yang menjadi pasien di Puskesmas Pedes Kab. Karawang dengan cara pengambilan sampel Purpossive sampling Terdapat 41 Responden yang termasuk kedalam kriteria inklusi. Hasil yang didapatkan adalah tidak ada hubungan yang signifikan antara variable independen (riwayat penyakit ibu, riwayat penyakit keluarga, sosial ekonomi, dukungan keluarga dan keteraturan ANC) dengan variable dependen yaitu kejadian Pre Eklampsia pada ibu hamil. Sesuai dengan wawancara dengan petugas kesehatan setempat Penulis berpendapat bahwa kejadian Pre Eklampsia yang termasuk kedalam kategori penyakit tertinggi di Puskesmas Pedes mempunyai keterkaitan dengan keadaan lingkungan sekitar, yang dimana letak daerah ini sangat dekat dengan lautan, sehingga tingginya kadar garam didalam air yang dikonsumsi oleh masyarakat sekitar termasuk para ibu hamil. Menghimbau kepada ibu hamil agar ibu hamil dapat memilih makanan yang dikonsumsi agar tidak terlalu banyak mengkonsumsi makanan yang terlalu banyak mengandung garam.
\end{abstract}

Kata Kunci : Pre eklampsia, Periksa ANC, Riwayat Penyakit, Sosial ekonomi

\begin{abstract}
Preeclampsia and eclampsia are diseases that are of particular concern in maternal and neonatal cases, because preeclampsia and eclampsia are one of the causes of high maternal and perinatal mortality, especially in developing countries. Until now, preeclampsia and eclampsia are "the disease of theories", because the number of people with preeclampsia and eclampsia remains high and results in high rates of morbidity and maternal mortality. The number of data found by case researchers of mothers who gave birth and suffered from preeclampsia at the time of delivery at the Pedes Health Center in 2014 was 103 cases (7.1\%), in 2015 it decreased by $3 \%$ to 98 cases (6.8\%), and in 2016 there were preeclampsia reaching 134 cases (12.4\%). The purpose of this study was to determine the causative factors for the incidence of pre-eclampsia, where many cases occur at this time, especially from indirect
\end{abstract}

http://ejournal.urindo.ac.id/index.php/kesehatan

Article History :

Sumbitted 01 Desember 2020, Accepted 29 Desember 2020, Published 31 Desember 2020 
causes such as: history of maternal disease, family history of disease, socioeconomic and ANC regularity. The method used in this study was a quantitative approach with a prospective cohort design, while the population in this study were third trimester pregnant women who became patients at the Pedes District Health Center. Karawang by means of purposive sampling. There were 41 respondents who were included in the inclusion criteria. The results obtained were that there was no significant relationship between the independent variables (history of maternal disease, family history of disease, socioeconomic, family support and ANC regularity) and the dependent variable, namely the incidence of pre-eclampsia in pregnant women. In accordance with interviews with local health workers, the author believes that the incidence of Pre-Eclampsia which is included in the highest category of disease in the Pedes Health Center is related to the surrounding environment, which is located very close to the ocean, so that high levels of salt in the water consumed by the surrounding community including pregnant women. Appeals to pregnant women so that pregnant women can choose the food they eat so they don't consume too much food that contains too much salt.

Keywords: Pre-eclampsia, ANC Check, History of Disease, Socio-economic

\section{PENDAHULUAN}

\section{A. Latar Belakang Masalah}

Preeklampsia serta eklampsia merupakan salah satu penyakit yang menjadi perhatian khusus pada kasus maternal dan neonatal, karena penyakit preeklampsia dan eklampsia ini adalah salah satu penyebab kematian ibu hamil dan perinatal yang tinggi terutama di negara berkembang. Sampai saat ini penyakit preeklampsia dan eklampsia merupakan "the disease of theories", karena jumlah angka penderita preeklampsia dan eklampsia tetap (Manuaba, 2010).

Salah satu masalah utama yang dialami oleh Indonesia adalah masalah kesehatan ibu dan anak yang harus dipecahkan sehingga tidak berkelanjutan. Hasil Survey Demografi Kesehatan Indonesia

(SDKI) tahun 2012 berdasarkan profil kesehatan Republik Indonesia tahun 2014 didapatkan bahwa angka kematian bayi (AKB) adalah 32 kematian per 1000 kelahiran hidup dan kematian balita adalah 40 kematian per 1000 kelahiran hidup (Kemenkes RI, 2014)

Menurut Profil Dinas Kesehatan Provinsi Jawa Barat (2012) diketahui Angka Kematian Ibu mencapai 86/100.000 KH. Sedangkan untuk di Kabupaten Karawang angka kematian ibu mencapai 61/100.000 KH (Dinas Kesehatan Karawang, 2016).

Penyebab langsung yang mengakibatkan kematian Ibu dan anak salah satunya adalah perdarahan (31,7\%), preeklampsia $(29,3 \%)$, infeksi $(5,6 \%)$, partus lama $(0,64 \%)$, abortus $(0,16 \%)$ dan penyebab lainnya (32,5\%) (Profil Kesehatan Jabar, 2013).

Data pasien yang mengalami preeklampsia pada ibu bersalin di Puskesmas Pedes tahun 2014 berjumlah 103 (7,1\%), pada tahun 2015 terdapat penurunan kejadian preeklampsia dengan jumlah 98 (6,8\%), sedangkan tahun 2016 terjadi peningkatan kembali dengan angka kejadian 
Jurnal Bidang IImu Kesehatan

preeklampsia mencapai 134 (12,4\%) dan

pada tahun 2017 terdapat 125 kasus (12,8\%)

(Profil Puskesmas Pedes, 2018).

B. Tujuan

1. Mengetahui riwayat penyakit ibu hamil yang mengalami Pre eklampsia

2. Mengetahui riwayat penyakit keluarga ibu hamil yang mengalami Pre eklampsia

3. Mengetahui sosial ekonomi ibu yang mengalami Pre Eklampsia

4. Mengetahui keteraturan pemeriksaan ANC yang mengalami Pre Eklampsia

5. Mengetahui hubungan antara faktor pencetus dengan kejadian Pre Eklampsia

\section{METODE PENELITIAN}

Penelitian ini menggunakan pendekatan kuantitatif dengan rancangan Kohort Prospektif. Populasi yang dipakai dalam penelitian ini adalah ibu hamil trimester 3 yang menjadi pasien di Puskesmas Pedes Kab. Karawang dengan cara pengambilan sampel Purpossive sampling. Terdapat 41 Responden yang termasuk kedalam kriteria inklusi, Data primer . Peneliti melakukan pengkajian dengan cara melakukan wawancara kepada seluruh responden setelah itu dilakukan masa tunggu sampai para responden bersalin untuk melihat apakah ibu hamil tersebut mengalami Pre eklampsia atau tidak.

\section{HASIL PENELITIAN}

\section{1. Hasil Analisis Univariat}

Tabel 1. Hasil Analisis Univariat

\begin{tabular}{lllll}
\hline No & Variabel & Klasifikasi & $\mathbf{N}$ & Presentase $\%$ \\
\hline $\mathbf{1}$ & Pre Eklampsia & Ya & 16 & 39,0 \\
\cline { 3 - 5 } & & Tidak & 25 & 61,0 \\
\hline $\mathbf{2}$ & Riwayat Penyakit Ibu & Ada & 4 & 9,8 \\
\cline { 3 - 5 } & & Tidak & 37 & 90,2 \\
\hline $\mathbf{3}$ & Riwayat Penyakit Keluarga & Ada & 10 & 24,4 \\
\cline { 3 - 5 } & & Tidak & 31 & 75,6 \\
\hline $\mathbf{4}$ & Sosail Ekonomi & Rendah (< UMR) & 32 & 78,0 \\
\cline { 3 - 5 } & & Tinggi (> UMR) & 9 & 22,0 \\
\hline $\mathbf{5}$ & Keteraturan ANC & Tidak Teratur & 9 & 22,0 \\
\cline { 3 - 5 } & & Teratur & 32 & 78,0 \\
\hline
\end{tabular}

Tabel 2. Hasil Analisis Bivariat

\begin{tabular}{lclc}
\hline \multicolumn{1}{c}{ Variabel Independen } & P-Value & \multicolumn{1}{c}{ Hasil } & OR \\
\hline Riwayat Penyakit Ibu & 0.632 & $\begin{array}{l}\text { Tidak Berhubungan }(P- \\
\text { Value }>0.05)\end{array}$ & $0,350(0,035-3,454)$ \\
\hline Riwayat Penyakit Keluarga & 0,712 & $\begin{array}{l}\text { Tidak Berhubungan }(P- \\
\text { Value }>0.05)\end{array}$ & $0,593(0,129-2.738))$ \\
\hline Sosial Ekonomi & 0.441 & $\begin{array}{l}\text { Tidak Berhubungan }(P- \\
\text { Value }>0.05)\end{array}$ & $2,722(0,488-15,198)$ \\
& & . & \\
\hline
\end{tabular}




$\begin{array}{lll}\text { Dukungan Keluarga } & 0,717 \quad \begin{array}{l}\text { Tidak Berhubungan }(P- \\ \text { Value }>0.05)\end{array} & 1,333(0,298-5.957)\end{array}$

Value $>0.05$ )

Tabel 2. menunjukkan bahwa seluruh hasil analisis statistik variabel menyatakan hubungan yang tidak signifikan

\section{PEMBAHASAN}

Berdasarkan hasil penelitian analisis univariat diperoleh bahwa sebagian besar ibu bersalin di Puskesmas Pedes Karawang tidak mengalami pre eklampsia yaitu berjumlah 25 orang (61\%) sedangkan yang mengalami Pre Eklampsia sebanyak 16 orang (39\%), meskipun terlihat lebih besar ibu yang tidak mengalami Pre Eklampsia akan tetapi jumlah ini termasuk jumlah yang besar dalam kondisi penyakit kebidanan karena sudah melebihi $10 \%$ dari jumlah ibu yang bersalin. Variabel riwayat penyakit ibu yang mempunyai riwayat penyakit Pre eklampsia pada persalinan sebelumnya sebanyak 4 orang $(9,8 \%)$ sedangkan yang tidak mempunyai riwayat penyakit Pre Eklampsia pada persalinan sebelumnya sebesar 37 orang $(90,2 \%)$. Variabel riwayat penyakit keluarga, ibu yang mempunyai keluarga yang beriwayat penyakit Hipertensi/Pre Eklampsia sebanyak 10 orang $(24,4 \%)$ sedangkan ibu yang tidak memiliki penyakit keluarga sebanyak 31 orang $(75,6 \%)$. Variabel sosial ekonomi ibu yang memiliki ekonomi rendah sebanyak 32 orang (78\%) sedangkan ibu yang memiliki eskonomi yang tinggi sebesar 9 orang (22\%). Variabel keteraturan ANC mempunyai hasil sebagai berikut, ibu yang melakukan ANC secara teratur memiliki jumlah sebesar 32 orang (78\%) sedangkan ibu yang tidak melakukan ANC secara teratur memiliki jumlah 9 orang (22\%).
Untuk hasil bivariat semua variabel memiliki $\mathrm{P}$ Value $>0,05$ yang artinya semua variabel tidak mempunyai hubungan dengan kejadian Pre Eklampsia pada ibu bersalin di Puskesmas Pedes Karawang.

Akan tetapi pada penelitian lain disebutkan bahwa faktor-faktor yang mempengaruhi kejadian pre eklampsia adalah umur ibu, pendidikan, umur kehamilan, paritas, ANC (legawati)

Pada penelitian ditemukan bahwa Faktor yang paling yang signifikan bermakna dan berhubungan dengan kejadian preeklampsia pada ibu hamil di RSUP Dr. Mohammad Hoesin Palembang yaitu umur ibu $>35$ tahun, obesitas dan riwayat hipertensi sedangkan untuk varibael lainnya tidak ada hubungan yang signifikan (Yudia gustri dkk)

Sesuai dengan wawancara dengan petugas kesehatan setempat Penulis berpendapat bahwa kejadian Pre Eklampsia yang termasuk kedalam kategori penyakit tertinggi di Puskesmas Pedes mempunyai keterkaitan dengan keadaan lingkungan sekitar, yang dimana letak daerah ini sangat dekat dengan lautan, sehingga tingginya kadar garam didalam air yang dikonsumsi oleh masyarakat sekitar termasuk para ibu hamil. 
5. Kesimpulan yang dapat diambil dari penelitian ini adalah:

Tidak ada hubungan antara semua variabel dependen (riwayat penyakit keluarga, riwayat penyakit ibu, sosial ekonomi, keteraturan ANC) dengan kejadian Pre Eklampsia pada ibu hamil di Karawang.

\section{DAFTAR PUSTAKA}

Departemen Kesehatan Jabar. (2016). Profil Kesehatan Jawa Barat Tahun 2013. Diperoleh dari http://DeskesJabar.go.id. Diunduh tanggal 21 Januari 2017.

Gustri Yudia, Sitorus Januar Rico, Utama Feranita. 2016. Determinan Kejadian Pre eklampsia Pada Ibu Hamil di RSUP DR. Mohammad Hoesin Palembang. Jurnal Ilmu Kesehatan Masyarakat.November 2016, 7 (3):209217. UNSRI

Kemenkes RI. (2016). Survey demografi kesehatan indonesia. Jakarta: Kemenkes RI Legawati, Utama Nang Randu.2017. Analisis Faktor Risiko Kejadian Pre Ekmalpsia Berat di RSUD Rujukan Kabupaten dan Provinsi Kalimantan Tengah. Jurnal Surya Medika volume 3 no.1. Poltekkes Kemenkes palangkaraya
Manuaba, IGB. (2010). Ilmu Kebidanan, Penyakit Kandungan dan Keluarga Berencana. Jakarta : EGC

Notoadmodjo,S. (2010). Metode Penelitian Kesehatan. Jakarta : Rineka Cipta Jakarta.

Prawirohardjo, Sarwono. (2002). Ilmu Kebidanan. Jakarta : Yayasan Bina Pustaka Sarwono Prawirohardjo. (2008). IImu Kebidanan. Jakarta : Yayasan Bina Pustaka Sarwono Prawirohardjo. (2012). Ilmu Kebidanan. Jakarta : Yayasan Bina Pustaka Sarwono Prawirohardjo.

Saifuddin, AB. (2007). Buku Acuan Nasional Pelayanan Kesehatan Maternal dan Neonatal. Jakarta : Yayasan Bina Pustaka Sarwono Prawirohardjo 